\title{
Comparison of Neuromuscular Blockade with Rocuronium in Young and Elderly Patients with or without Renal Failure
}

\author{
${ }^{1}$ SK Gvalani, ${ }^{2}$ L Pradeep
}

\begin{abstract}
Context: The duration of neuromuscular block with rocuronium is affected by old age as well as renal impairment. It would be helpful for anesthetists to know the variation in the block in elderly patients with renal failure and the significance of neuromuscular monitoring in this group.
\end{abstract}

Aim: The aim of our study is to investigate the neuromuscular effects of $0.6 \mathrm{mg} / \mathrm{kg}$ rocuronium under general anesthesia in young adults and elderly patients with or without renal failure.

Study design: Prospective randomized controlled study.

Materials and methods: Young and elderly 100 patients were divided into 4 groups of 25 each, with or without renal failure. General anesthesia with propofol $2 \mathrm{mg} \mathrm{kg}$ intravenous (iv), fentanyl $2 \mu \mathrm{g} \mathrm{kg}$ iv, and $60 \% \mathrm{~N}_{2} \mathrm{O}$ in $\mathrm{O}_{2}$ were given. Neuromuscular monitoring was started immediately after the induction of anesthesia and before the administration of muscle relaxant. After the stabilization of control responses, $0.6 \mathrm{mg} \mathrm{kg}$ rocuronium was injected intravenously. The onset time, time to achieve maximum block, and the recovery times were noted.

Statistical analysis used: The statistical analysis of the data from the study was performed with the Statistical Package for the Social Sciences (SPSS) software for Window Release 14.0. One-way analysis of variance, Bonferroni's, and chi-square test were used to compare patients' characteristics.

Results: The duration of block as well as the recovery indices were significantly prolonged in the elderly compared to the young patients. Maximum prolongation was observed in the elderly group with renal failure. This underlines the importance of neuromuscular monitoring in these patients.

Keywords: Neuromuscular block, Renal failure, Rocuronium. How to cite this article: Gvalani SK, Pradeep L. Comparison of Neuromuscular Blockade with Rocuronium in Young and Elderly Patients with or without Renal Failure. Res Inno in Anesth 2016;1(2):45-51.

Source of support: Nil

Conflict of interest: None

\footnotetext{
${ }^{1}$ Additional Professor and Head, ${ }^{2}$ Ex-Resident

${ }^{1}$ Department of Anesthesia, HBT Medical College and Dr RN Cooper Municipal General Hospital, Mumbai, Maharashtra, India

${ }^{2}$ Department of Anesthesia, King Edward Memorial Hospital and Seth Gordhandas Sunderdas Medical College, Mumbai Maharashtra, India

Corresponding Author: SK Gvalani, Additional Professor and Head, Department of Anesthesia, HBT Medical College and Dr RN Cooper Municipal General Hospital, Mumbai, Maharashtra India, Phone: +919920521161, e-mail: skgvalani@live.com
}

\section{INTRODUCTION}

Rocuronium bromide is an aminosteroidal, nondepolarizing, neuromuscular blocking agent. It is widely used during anesthesia for its short onset time and intermediate duration of action. The pharmacokinetic profile of rocuronium resembles that of vecuronium. However, rocuronium has no metabolites as opposed to vecuronium. In common with vecuronium, hepatic uptake and biliary excretion have been suggested to be the main mechanism of rocuronium metabolism with renal elimination accounting for only 10 to $20 \%$ of its overall excretion. Rocuronium clearance is decreased and the duration of neuromuscular block prolonged during general anesthesia in patients with end-stage renal disease.

We chose to investigate the effects of aging and renal failure on the time course of action and recovery of rocuronium.

\section{AIM}

The aim of our study is to investigate the neuromuscular effects of $0.6 \mathrm{mg} / \mathrm{kg}$ rocuronium under general anesthesia in young adults and elderly patients with or without renal failure.

\section{OBJECTIVES}

- To evaluate the effects of aging and impaired renal function on the onset time and on the time taken for maximum blockade with $0.6 \mathrm{mg} / \mathrm{kg}$ rocuronium.

- To evaluate the impact of altered renal function on times to recovery of the first twitch $\mathrm{T}_{1}$ to $25,50,75,90 \%$ and of Train of Four (TOF) ratio to $70 \%$ and recovery index (RI).

- To evaluate the effects of aging on times to recovery of the first twitch $\mathrm{T}_{1}$ to $25,50,75,90 \%$ and of TOF ratio to $70 \%$ and RI.

\section{MATERIALS AND METHODS}

The sample size chosen for this prospective randomized controlled study was of 100 patients and the patients were divided into 2 groups.

The 1st group had 50 patients with normal renal function, which was further divided into 25 young (18-50 years) and 25 elderly ( $>65$ years). 
The 2nd group had 50 patients with renal failure, which was further divided into 25 young (18-50 years) and 25 elderly ( $>65$ years).

These patient groups were named as:

Y (S) Young adults

Y (C) Young adults

- Renal failure group $(n=25)$

- Normal renal function group $(\mathrm{n}=25)$

E (S) Elderly patients $\quad-\quad$ Renal failure group $(n=25)$

E (C) Elderly patients - Normal renal function group $(n=25)$

\section{Inclusion Criteria}

- American society of anesthesiologists (ASA) I, II, and III

- Mallampatti class I, II

- Age: Young group between 18 and 50 years and elderly group $>65$ years

- Renal failure group: Patients with creatinine clearance $<15 \mathrm{~mL} /$ minute.

\section{Exclusion Criteria}

- Patients who refuse consent

- ASA IV

- Anticipated difficult intubation

- Patients requiring drugs that are known to interfere with neuromuscular function of rocuronium

- Patients with burns and trauma

- Pregnancy

- Obesity (wt $>130 \%$ of ideal body weight)

- Hepatic and neuromuscular disorder.

\section{Study Procedure}

Institutional Ethics Committee approval was obtained. A thorough preoperative evaluation was done. Baseline investigations, such as hemoglobin $(\mathrm{Hb})$, total count (TC), differential count (DC), X-ray chest, electrocardiogram (ECG), renal function test (RFT), and liver function test (LFT) as well as special investigations as indicated were performed.

Informed consent was obtained from all patients. Patients were kept nil by mouth for at least 6 hours prior to surgery. Preoperative vital parameters in the form of baseline pulse, temperature, BP, and respiratory rate were recorded. All patients with renal failure were allowed to continue medications for essential therapy of renal failure. The patients in our study did not receive any premedication.

\section{Preinduction}

When the patient arrived to the operation theater, standard monitoring devices like pulse oximeter, cardioscope, and sphygmomanometry were attached. Oxygen at 5 to $6 \mathrm{~L} /$ minute with Hudson mask was administered. Electrodes of TOF guard were connected and supramaximal stimulus and the basal TOF were noted.

\section{Standard Intraoperative Monitoring}

- ECG with defibrillator

- Noninvasive BP

- Pulse oximeter

- Capnography.

\section{Anesthetic Induction}

General anesthesia with propofol $2 \mathrm{mg} \mathrm{kg}$ intravenous (iv), fentanyl $2 \mu \mathrm{g} \mathrm{kg}$ iv, and $60 \% \mathrm{~N}_{2} \mathrm{O}$ in $\mathrm{O}_{2}$ were given. Neuromuscular monitoring was started immediately after the induction of anesthesia and before the administration of muscle relaxant. The forearm was immobilized in splint and neuromuscular transmission was monitored using a peripheral nerve stimulator. The ulnar nerve was stimulated supramaximally at the wrist every 15 seconds via the cutaneous electrodes using TOF nerve stimulation. After the stabilization of control responses, $0.6 \mathrm{mg} \mathrm{kg}$ rocuronium was administered. Tracheal intubation was performed at the time of maximum depression of the twitch. Anesthesia was maintained with propofol 100 to $200 \mathrm{micr} / \mathrm{kg} /$ minute iv, $60 \% \mathrm{~N}_{2} \mathrm{O}$ in $\mathrm{O}_{2}$, and supplemental $50 \mu \mathrm{g}$ fentanyl as required and controlled ventilation to maintain end tidal $\mathrm{CO}_{2}$ between 35 and $40 \mathrm{~mm} \mathrm{Hg}$.

The following times were recorded from the end of injection of rocuronium:

- Onset time

- Time to maximum block

- Time to recovery of:

- First twitch response to $25 \%$

- First twitch response to 50,75 , and $90 \%$ of baseline

- Time to recovery of TOF ratio to $70 \%$

- Recovery index, i.e., time from 25 to $75 \%$ twitch height recovery.

\section{Statistical Analysis}

The statistical analysis of the data from the study was performed with the Statistical Package for the Social Sciences (SPSS) for Window Release 14.0. One-way analysis of variance, Bonferroni's, and chi-square test were used to compare patients' characteristics. The t test was used to compare the pharmacodynamic data between the groups. The results are presented as mean \pm standard deviation and $p<0.05$ is considered statistically significant.

\section{RESULTS}

- The onset time and the time taken for the maximum block in study groups were comparable with the control group as there was no statistically significant difference (Tables 1A and B, Graphs 1A and B).

- The times to recovery of the first twitch $\mathrm{T}_{1}$ to $25,50,75$, $90 \%$ and TOF to $70 \%$ and the RI were found to be prolonged in both young and elderly patients with renal failure compared to those with normal renal function. 
Table 1A: Comparison of RI between the young control group and elderly control group

\begin{tabular}{|c|c|c|c|c|c|c|c|c|c|c|}
\hline \multirow[b]{2}{*}{$R I(m)$} & \multicolumn{4}{|c|}{ Young normal renal function } & \multicolumn{4}{|c|}{ Elderly normal renal function } & \multirow[b]{2}{*}{ Unpaired t-test } & \multirow[b]{2}{*}{$p$-value } \\
\hline & Mean & Std. Dev. & Median & $I Q R$ & Mean & Std. Dev. & Median & $I Q R$ & & \\
\hline $\mathrm{RI}(\mathrm{m})$ & 13.00 & 3.40 & 14.00 & 6.00 & 22.36 & 3.38 & 23.00 & 4.00 & 9.761 & 0 \\
\hline
\end{tabular}

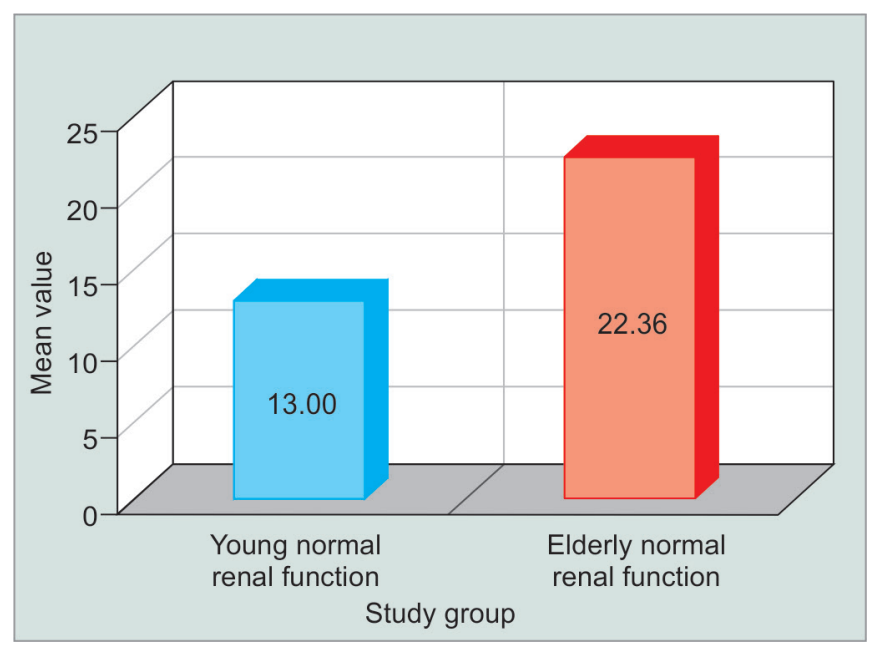

Graph 1A: Comparison of RI between young control/elderly control

Table 1B: T values in young control and elderly control

\begin{tabular}{|c|c|c|c|c|c|c|c|c|c|c|}
\hline \multirow[b]{2}{*}{$T 25(m)$} & \multicolumn{4}{|c|}{ Young normal renal function } & \multicolumn{4}{|c|}{ Elderly normal renal function } & \multirow[b]{2}{*}{ Unpaired t-test } & \multirow[b]{2}{*}{$p$-value } \\
\hline & Mean & Std. Dev. & Median & $I Q R$ & Mean & Std. Dev. & Median & $I Q R$ & & \\
\hline T25 (m) & 20.12 & 4.24 & 19.00 & 4.00 & 40.56 & 8.12 & 41.00 & 10.00 & 11.154 & 0 \\
\hline $\mathrm{T} 50(\mathrm{~m})$ & 26.92 & 5.76 & 27.00 & 6.00 & 52.24 & 8.92 & 52.00 & 12.00 & 11.926 & 0 \\
\hline $\mathrm{T} 75(\mathrm{~m})$ & 33.12 & 6.92 & 32.00 & 8.00 & 62.92 & 9.85 & 63.00 & 14.00 & 12.376 & 0 \\
\hline T90 (m) & 40.48 & 9.39 & 41.00 & 13.00 & 75.56 & 13.39 & 74.00 & 24.00 & 10.727 & 0 \\
\hline TOF $0.7(\mathrm{~m})$ & 31.32 & 6.81 & 31.00 & 7.00 & 60.56 & 9.84 & 60.00 & 14.00 & 12.212 & 0 \\
\hline
\end{tabular}

Table 1B continued

\begin{tabular}{|c|c|c|c|c|c|}
\hline \multicolumn{2}{|c|}{ Mann-Whitney test } & \multicolumn{2}{|c|}{ Young normal renal function } & \multicolumn{2}{|c|}{ Elderly normal renal function } \\
\hline$Z$ value & $p$-value & Minimum & Maximum & Minimum & Maximum \\
\hline 5.918 & 0.000 & 14.00 & 30.00 & 25.00 & 25.00 \\
\hline 5.947 & 0.000 & 18.00 & 39.00 & 37.00 & 37.00 \\
\hline 6.063 & 0.000 & 21.00 & 46.00 & 47.00 & 47.00 \\
\hline 5.966 & 0.000 & 25.00 & 60.00 & 56.00 & 56.00 \\
\hline 6.054 & 0.000 & 20.00 & 45.00 & 45.00 & 45.00 \\
\hline
\end{tabular}

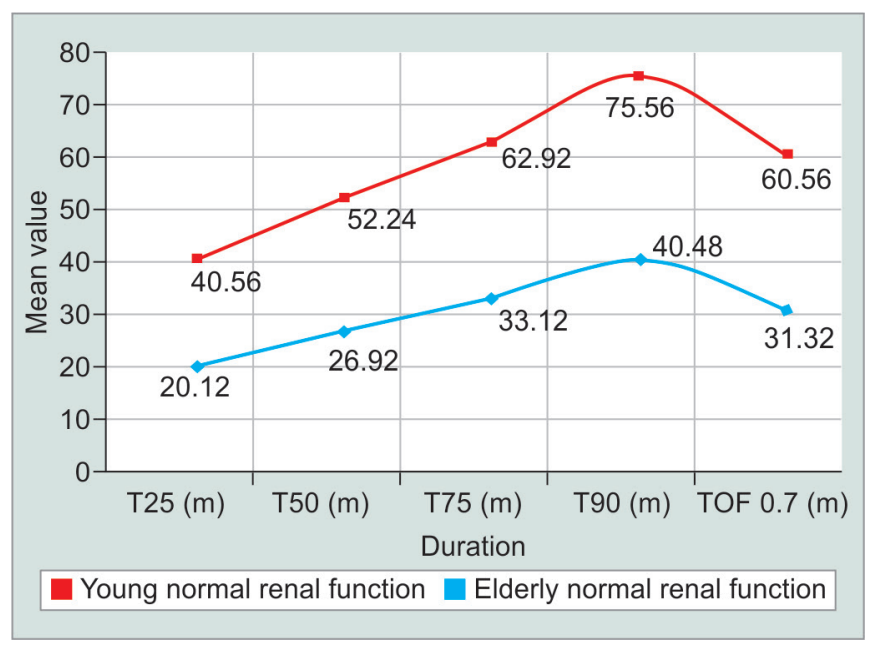

Graph 1B: Comparison of $\mathrm{T}$ in young (C)/elderly (C) 
- The times to recovery of the first twitch $\mathrm{T}_{1}$ to 25, $50,75,90 \%$ and TOF to $70 \%$ and the RI were found to be prolonged in elderly when compared with young adults. (Tables 2A and 2B, Graphs 2A and 2B, Tables 3A and 3B, Graphs 3A and 3B).

\section{DISCUSSION}

The two major factors that affect the duration of neuromuscular blockade by rocuronium are age and renal failure. It can be used safely in elderly patients if anesthetist is aware of the altered pharmacokinetics in this

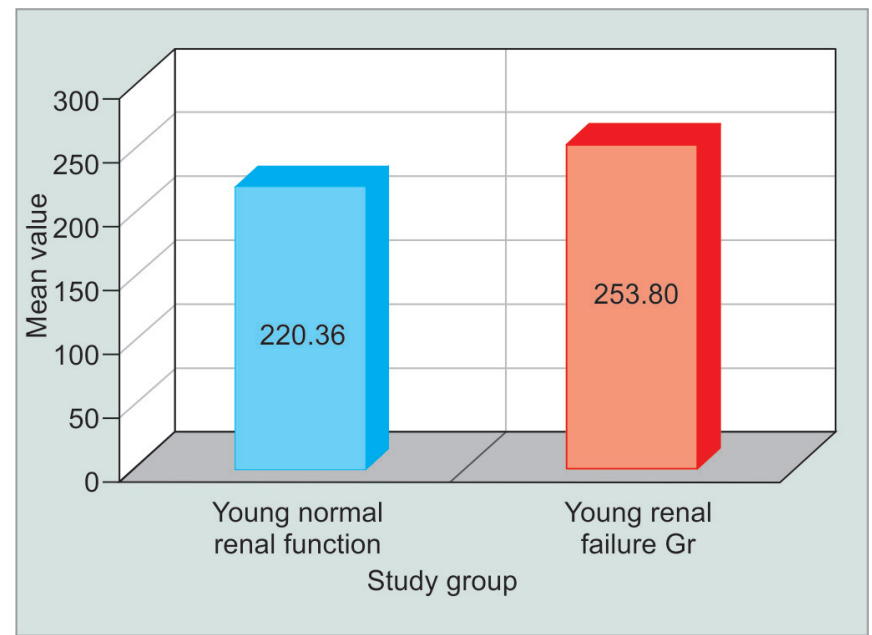

Graph 2: Comparison of time taken for maximum block between young control group and young renal failure group. The time taken for maximum block in young control group was $220 \pm 36$ seconds and in young renal failure group was $253 \pm 80$ seconds. Time taken for maximum block in young renal failure group is significantly prolonged

Table 2A: Comparison of $\mathrm{T}$ values between young control group and young renal failure group

\begin{tabular}{|c|c|c|c|c|c|c|c|c|c|c|}
\hline \multirow[b]{2}{*}{$T 25(m)$} & \multicolumn{4}{|c|}{ Young normal renal function } & \multicolumn{4}{|c|}{ Young renal failure $\mathrm{Gr}$} & \multirow[b]{2}{*}{ Unpaired t-test } & \multirow[b]{2}{*}{$p$-value } \\
\hline & Mean & Std. dev. & Median & $I Q R$ & Mean & Std. dev. & Median & $I Q R$ & & \\
\hline T25 (m) & 20.12 & 4.24 & 19.00 & 4.00 & 51.16 & 9.27 & 51.00 & 14.00 & 15.231 & 0 \\
\hline T50 (m) & 26.92 & 5.76 & 27.00 & 6.00 & 65.28 & 10.06 & 66.00 & 15.00 & 16.551 & 0 \\
\hline T75 (m) & 33.12 & 6.92 & 32.00 & 8.00 & 76.96 & 11.34 & 79.00 & 15.00 & 16.504 & 0 \\
\hline T90 (m) & 40.48 & 9.39 & 41.00 & 13.00 & 88.68 & 13.26 & 88.00 & 22.00 & 14.833 & 0 \\
\hline TOF $0.7(\mathrm{~m})$ & 31.32 & 6.81 & 31.00 & 7.00 & 74.00 & 10.72 & 76.00 & 15.00 & 16.806 & 0 \\
\hline
\end{tabular}

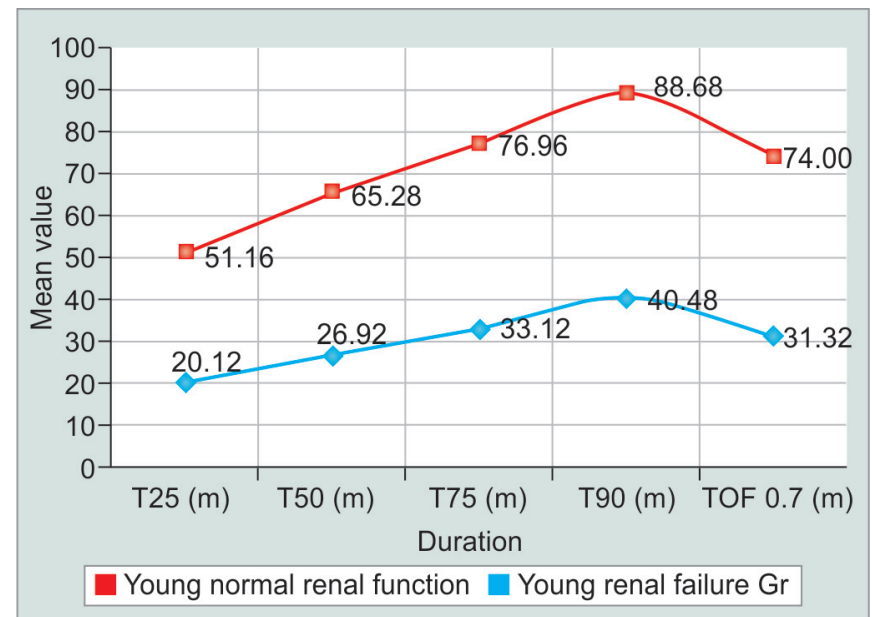

Graph 2A: Comparison of T young (C)/young (S) 
Table 2B: Comparison of RI between young control group and young renal failure group

\begin{tabular}{|c|c|c|c|c|c|c|c|c|c|c|}
\hline \multirow[b]{2}{*}{$R I(m)$} & \multicolumn{4}{|c|}{ Young normal renal function } & \multicolumn{4}{|c|}{ Young renal failure $\mathrm{Gr}$} & \multirow[b]{2}{*}{ Unpaired t-test } & \multirow[b]{2}{*}{$p$-value } \\
\hline & Mean & Std. dev. & Median & $I Q R$ & Mean & Std. dev. & Median & $I Q R$ & & \\
\hline $\mathrm{RI}(\mathrm{m})$ & 13.00 & 3.40 & 14.00 & 6.00 & 25.80 & 5.21 & 25.00 & 5.00 & 10.281 & 0 \\
\hline
\end{tabular}

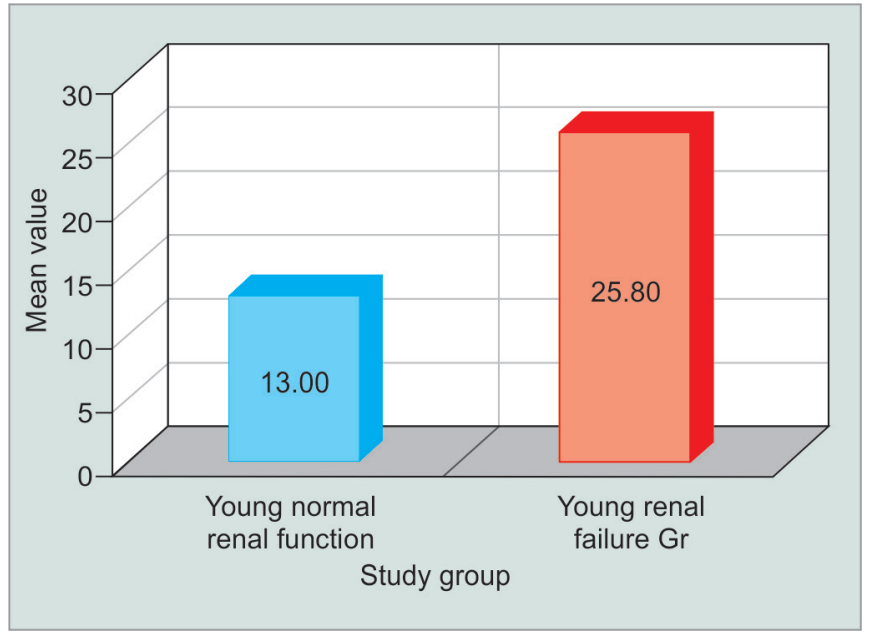

Graph 2B: Comparison of RI young (C)/young (S) group

Table 3A: Comparison of $T$ values between elderly control group and elderly renal failure group

\begin{tabular}{|c|c|c|c|c|c|c|c|c|c|c|}
\hline \multirow[b]{2}{*}{$T 25(m)$} & \multicolumn{4}{|c|}{ Elderly normal renal function } & \multicolumn{4}{|c|}{ Elderly renal failure $\mathrm{Gr}$} & \multirow[b]{2}{*}{ Unpaired t-test } & \multirow[b]{2}{*}{$p$-value } \\
\hline & Mean & Std. dev. & Median & $I Q R$ & Mean & Std. dev. & Median & $I Q R$ & & \\
\hline T25 (m) & 40.56 & 8.12 & 41.00 & 10.00 & 55.52 & 12.90 & 59.00 & 22.00 & 4.907 & 0 \\
\hline $\mathrm{T} 50(\mathrm{~m})$ & 52.24 & 8.92 & 52.00 & 12.00 & 73.40 & 13.85 & 73.00 & 23.00 & 6.424 & 0 \\
\hline T75 (m) & 62.92 & 9.85 & 63.00 & 14.00 & 87.44 & 15.16 & 89.00 & 20.00 & 6.782 & 0 \\
\hline T90 (m) & 75.56 & 13.39 & 74.00 & 24.00 & 101.60 & 18.06 & 103.00 & 23.00 & 5.791 & 0 \\
\hline TOF $0.7(\mathrm{~m})$ & 60.56 & 9.84 & 60.00 & 14.00 & 85.12 & 15.09 & 87.00 & 20.00 & 6.817 & 0 \\
\hline
\end{tabular}

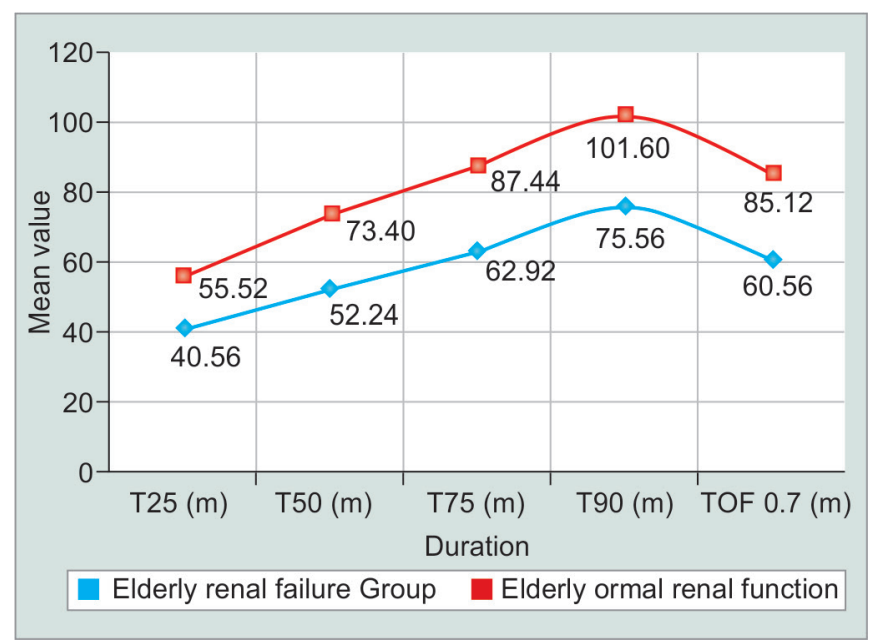

Graph 3A: Comparison of T in elderly (C)/elderly (S) group

Table 3B: Comparison of RI in elderly (C)/elderly (S)

\begin{tabular}{|c|c|c|c|c|c|c|c|c|c|c|}
\hline \multirow[b]{2}{*}{$R I(m)$} & \multicolumn{4}{|c|}{ Elderly normal renal function } & \multicolumn{4}{|c|}{ Elderly renal failure $\mathrm{Gr}$} & \multirow[b]{2}{*}{ Unpaired t-test } & \multirow[b]{2}{*}{$p$-value } \\
\hline & Mean & Std. dev. & Median & $I Q R$ & Mean & Std. dev. & Median & IQR & & \\
\hline $\mathrm{RI}(\mathrm{m})$ & 22.36 & 3.38 & 23.00 & 4.00 & 31.84 & 4.67 & 32.00 & 6.00 & 8.225 & 0 \\
\hline
\end{tabular}




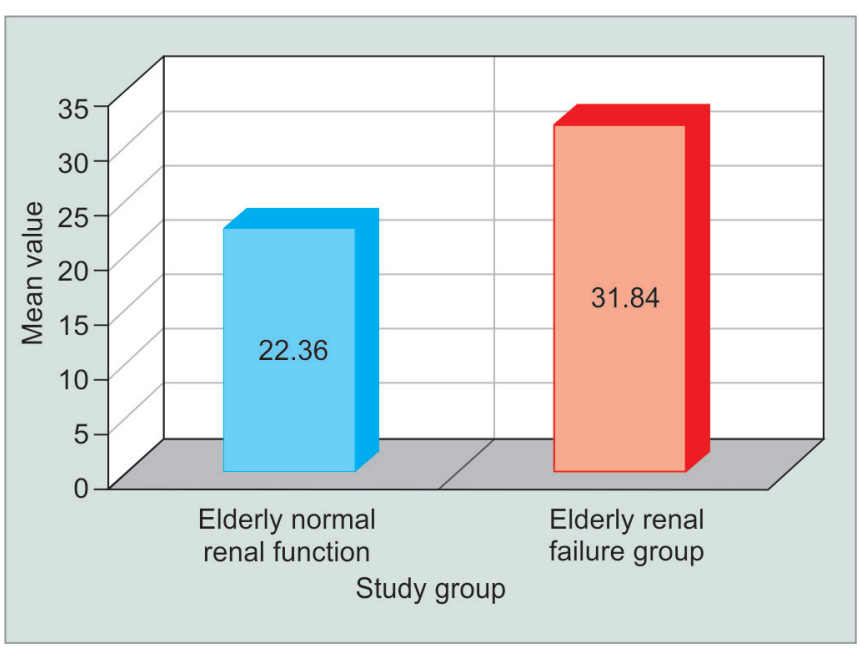

Graph 3B: Comparison of RI in elderly (C)/elderly (S)

patient group. Drug dosage and dose intervals are altered accordingly. An elderly patient with renal failure can pose a challenge and the use of a peripheral nerve stimulator can be invaluable.

The inhalational anesthetics have been shown to augment the intensity and duration of neuromuscular blockade by nondepolarizing muscle relaxants, including rocuronium bromide ${ }^{1-3}$ Hence, inhalational agents were not used in our study.

\section{Effect of Age on Rocuronium Neuromuscular Block}

A reduction in liver size and the splanchnic blood flow would affect those drugs that have a high liver extraction ratio (>0.7). In 2001, Sparr et $\mathrm{al}^{4}$ showed that rocuronium is primarily eliminated via the liver and its pharmacokinetic profile is similar to that of vecuronium bromide (vecuronium). The neuromuscular blocking agents that undergo a significant degree of organ-dependent elimination, such as pancuronium, vecuronium, and rocuronium have a prolonged duration of action in elderly as shown by various studies. ${ }^{5-8}$

In our study, there was no significant difference in the onset times and in time taken for the maximum block between the young and the elderly control group. Xiaobo et $\mathrm{al}^{9}$ concluded that the time of onset was comparable between the elderly and adult patients receiving cisatracurium or rocuronium.

This is most likely a reflection of multiple factors. The initial volume of distribution is the same for both groups. Thus in both groups the acetylcholine receptors at neuromuscular junction are presented initially with the same concentration. The concentration-response studies for rocuronium demonstrate that there is no difference in receptor sensitivity between the elderly and the younger controls. As a result, given an equal initial concentration of rocuronium, one would expect an equal initial action in both groups. The age-related changes occur in the neuromuscular junction, but the sensitivity of acetylcholine receptor to neuromuscular blocking agents is not much affected by advanced age. ${ }^{10}$

The physiological changes associated with aging, such as decreased total body water, decreased lean body mass, and changes in serum albumin levels may reduce the volume of distribution at steady state. The accompanying changes in the cardiovascular system decreased splanchnic and renal blood flow; lower glomerular filtration rate and smaller liver mass may decrease the rate of elimination of neuromuscular blocking agents.

Thus the differences in distribution and elimination have been suggested to explain the prolonged duration of action of neuromuscular blocking agents in the elderly.

\section{CONTROL}

In our study, all the recovery indices, including the RI, were found to be significantly prolonged in the elderly group. Furuya et $\mathrm{al}^{11}$ found that the time from rocuronium injection to reappearance of the first response to post tetanic count stimulation was approximately twofold longer and more variable in older patients than in younger patients. They suggested that the dosing interval of rocuronium should be adjusted using neuromuscular monitoring when maintaining intense neuromuscular block, especially in older patients.

In a similar study, Matteo et $\mathrm{al}^{5}$ concluded that the onset time of rocuronium was similar for both groups while the duration of action was significantly prolonged in the elderly compared with the younger control group.

\section{EFFECT OF RENAL FAILURE}

Impaired kidney function leads to alterations in pharmacokinetic parameters due to reduced glomerular filtration and altered tubular secretion and reabsorption. Plasma protein binding and the distribution and metabolism of drugs may also be altered in end-stage renal disease. Dosages of drugs cleared by the kidney should be adjusted according to creatinine clearance.

\section{Onset Time and Time Taken for the Maximum Block}

The time of onset of action did not differ significantly between the groups with normal or impaired renal function. The time taken for the maximum block is comparable between the elderly study group and elderly controls. But, it is significantly prolonged in younger renal failure group.

\section{RECOVERY INDICES}

All the recovery indices, including the RI, were found significantly prolonged in both young and elderly groups with renal failure. 
Kocabas et $\mathrm{al}^{12}$ in the year 2008, Kalezić et $\mathrm{al}^{13}$ in 2011, and Staals et al $^{14}$ in 2010 found prolongation of action in patients with renal failure.

Robertson et $\mathrm{al}^{15}$ studied the pharmacodynamics of rocuronium $0.3 \mathrm{mg} \mathrm{kg}^{(-1)}$ in adult patients with and without renal failure. They did not find any statistical difference in the neuromuscular blocking effects of rocuronium between the two groups but there was a wide range of variability in the total duration of block.

They concluded that rocuronium $0.3 \mathrm{mg} \mathrm{kg}$ is a useful dose of rocuronium in patients with renal failure when short periods of neuromuscular blockade are required. This study highlighted the role, under propofol anesthesia, of this lower dose of rocuronium in achieving elective endotracheal intubation in patients with renal failure. With this lower dose of rocuronium, the neuromuscular block produced can be antagonized within 20 minutes.

Verbeeck and Musuamba ${ }^{16}$ commented on pharmacokinetics and dose adjustments in renal dysfunction. The authors reported that when fractional excretion for a drug is $>0.3$, a dosage adjustment is most likely required at least in patients with severe renal impairment, and when the fractional excretion is $<0.3$, the drug is eliminated from the body by nonrenal mechanisms, usually by metabolism. Since it has been shown that drug metabolism may be altered in patients with chronic renal failure, dosage adjustment may also be necessary for these drugs to avoid excessive accumulation of the drug.

Fractional excretion of rocuronium is $<0.3$. So, adequate dose adjustment and appropriate neuromuscular monitoring is indicated.

In conclusion, although the duration of action of rocuronium is increased in patients with reduced renal function, rocuronium is an acceptable neuromuscular blocking agent even for renal transplant patients with supportive peripheral neuromuscular monitoring.

\section{REFERENCES}

1. Bock M, Klippel K, Nitsche B, Bach A, Martin E, Motsch J. Rocuronium potency and recovery characteristics during steady-state desflurane, sevoflurane, isoflurane or propofol anaesthesia. Br J Anaesth 2000 Jan;84(1):43-47.

2. Dragne A, Varin F, Plaud B, Donati F. Rocuronium pharmacokinetic-pharmacodynamic relationship under stable propofol or isoflurane anesthesia. Can J Anaesth 2002 Apr;49(4):353-360.
3. Xue FS, Liao X, Tong SY, Liu JH, An G, Luo LK. Dose-response and time-course of the effect of rocuronium bromide during sevoflurane anaesthesia. Anaesthesia 1998 Jan;53(1): 25-30.

4. Sparr HJ, Beaufort TM, Fuchs-Buder T. Newer neuromuscular blocking agents: how do they compare with established agents? Drugs 2001;61(7):919-942.

5. Matteo RS, Ornstein E, Schwartz AE, Ostapkovich N, Stone JG. Pharmacokinetics and pharmacodynamics of rocuronium (Org 9426) in elderly surgical patients. Anesth Analg 1993 Dec;77(6):1193-1197.

6. Duvaldestin P, Saada J, Berger JL, D'Hollander A, Desmonts JM. Pharmacokinetics, pharmacodynamics, and dose-response relationships of pancuronium in control and elderly subjects. Anesthesiology 1982 Jan;56(1):36-40.

7. Slavov V, Khalil M, Merle JC, Agostini MM, Ruggier R, Duvaldestin P. Comparison of duration of neuromuscular blocking effect of atracurium and vecuronium in young and elderly patients. Br J Anesth 1995 Jun;74(6):709-711.

8. Bevan DR, Fiset P, Balendran P, Law-Min JC, Ratcliffe A, Donati F. Pharmacodynamic behaviour of rocuronium in the elderly. Can J Anaesth 1993 Feb;40(2):127-132.

9. Xiaobo F, Jianjuan K, Yanlin W. Comparison of the variability of the onset and recovery from neuromuscular blockade with cisatracurium versus rocuronium in elderly patients under total intravenous anesthesia. Braz J Med Biol Res 2012 Jul;45(7):676-680.

10. Corsonello A, Pedone C, Incalzi RA. Age-related pharmacokinetic and pharmacodynamic changes and related risk of adverse drug reactions. Curr Med Chem 2010;17(6):571-584.

11. Furuya T, Suzuki T, Kashiwai A, Konishi J, Aono M, Hirose N, Kato J, Ogawa S. The effects of age on maintenance of intense neuromuscular block with rocuronium. Acta Anaesthesiol Scand 2012 Feb;56(2):236-239.

12. Kocabas S, Yedicocuklu D, Askar FZ. The neuromuscular effects of $0.6 \mathrm{mg} \mathrm{kg}^{(-1)}$ rocuronium in elderly and young adults with or without renal failure. Eur J Anaesthesiol 2008 Nov;25(11):940-946.

13. Kalezić N, Krivić B, Živaljević V, Ugrinović D, Jovanović D, Marković D, Veličković J, Ladjević N. Characteristics of neuromuscular block after administration of rocuronium bromide in patients with end-stage renal failure. Srp Arh Celok Lek 2011 Nov-Dec;139(11-12):765-771.

14. Staals LM, Snoeck MM, Driessen JJ, van Hamersvelt HW, Flockton EA, van den Heuvel MW, Hunter JM. Reduced clearance of rocuronium and sugammadex in patients with severe to end-stage renal failure: a pharmacokinetic study. Br J Anaesth 2010 Jan;104(1):31-39.

15. Robertson EN, Driessen JJ, Vogt M, De Boer H, Scheffer GJ. Pharmacodynamics of rocuronium $0.3 \mathrm{mg} \mathrm{kg}(-1)$ in adult patients with and without renal failure. Eur J Anaesthesiol 2005 Dec;22(12):929-932.

16. Verbeeck RK, Musuamba FT. Pharmacokinetics and dosage adjustment in patients with renal dysfunction. Eur J Clin Pharmacol 2009 Aug;65(8):757-773. 